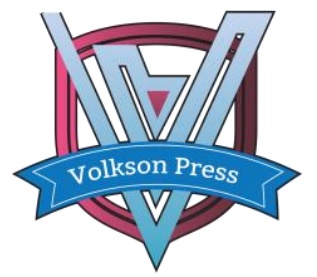

Contents List available at VOLKSON PRESS

Economics \& Management Innovations(EMI)

DOI : http://doi.org/10.26480/icemi.01.2017.407.412

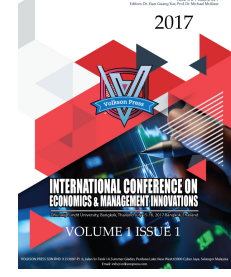

\title{
Influential Factors Affecting Small Hotel Performance
}

\author{
Nuntasaree Sukato ${ }^{1, *}$ \\ ${ }^{1}$ College of Innovation Business Administration and Accountancy, Dhurakij Pundit University, Bangkok, Thailand \\ *nuntasaree.suk@dpu.ac.th
}

This is an open access article distributed under the Creative Commons Attribution License, which permits unrestricted use, distribution, and reproduction in any medium, provided the original work is properly cited.

\section{ARTICLE DETAILS}

\section{Article History:}

Received 02 october 2017 Accepted 06 october 2017 Available online 11 october 2017

\section{Keywords:}

Hotel; Market Orientation;

Performance; Thailand; Tourism..

\section{ABSTRACT}

The research examines associations among three factors that are market orientation, innovation, and performance, and explores to what extent the market orientation and innovation affects the degree of performance. A mixed method is a methodology for conducting this study. The unit of analysis is small hotels located in the Bangkok metropolitan region. First, a quantitative approach will be employed. Questionnaires were distributed to owners or managers in charge of marketing functions, and 212 returned questionnaires were usable. Structural equation modeling was employed to analyze the results. Later, the qualitative method was used by means of in-depth interview with 22 experts in the hotel industry. The results show that market intelligence generation, the dissemination of intelligence, and responsiveness, to generation have significant indirect effects on business performance via innovation. The results of in-depth interviews also support the quantitative findings. The findings add a body of knowledge to the area of tourism marketing, and reveal understanding with regard to small hotels in the hotel business.

\section{Introduction}

In Thailand, the overall tourism sector represented 63.7 billion US dollars or 17.0 percent of GDP in 2015, and is expected to grow over the next 10 years to generate approximately 120 billion US dollars, or 19.6 percent of GDP, and create a total of 7.5 million jobs by $2023[1,2]$ as the economy is progressing towards a more developed economy. This trend is consistent with those of more developed countries. Therefore, the tourism industry is regarded as a key segment of the Thai economy. Furthermore, the Thai government has conducted a strategic policy of preparation for small and medium enterprises (SMEs) in the tourism industry entering the ASEAN Economic Community (AEC) in 2015.

Several differences between small and larger enterprises in terms of characteristics may be noted. For example, small businesses tend to be intrinsically more innovative, especially in the early stages of the industry life cycle [3]. Smaller firms are also likely to have more customer contact, a greater propensity for action, and more output flexibility than larger firms [4]. Small and larger businesses are also likely to differ with respect to resources [5], such as assets, capabilities, information, and these resources are often the key to sustained competitive advantage and superior performance. It is possible that small enterprises may be quite distinct from larger companies in terms of how they integrate various elements, such as information processing, knowledge, and responsiveness, into a unique strategic resource. While they may not have as many resources as larger firms, this ability to develop unique strategic resources could be a key distinguishing feature of small firms.

In this paper, the hotel segment was chosen because it belongs to the tourism industry and is regarded as a significant service sector in the Thai economy. As reported by Kasikorn Research Center [6], the performance of the hotel industry in Thailand has just rebounded from the decline in tourist arrivals due to anti-government demonstrations occurring the first half of 2014, followed by the declaration of martial law, and civil unrest. Meanwhile, 3-5 star hotels have expanded their businesses in terms of the numbers of both operational beds and registered hotel properties. As of September 2014, approximately new 101 hotels, comprising about 18,000 rooms, were introduced into the industry. The new hotels were mainly located in Bangkok and Phuket [7]. This situation could lead to intensifying price competition among hotels, resulting in the oversupply of hotel rooms. Small hotels tend to suffer more because of limited resources, while up-scale hotels are likely to suffer less.
Therefore, small hotels in Thailand must continually enhance their business performance in order to survive and achieve sustainability owing to the pressures of a highly competitive environment.

\section{Objectives}

This paper extends the body of knowledge in small hotel business performance. The objectives are twofold: (1) to identify the effect of market orientation in terms of intelligence generation, dissemination and responsiveness on small hotel business performance; and (2) to confirm the effect of market orientation on small hotel performance from the perspective of experts in the hotel industry.

\section{Literature Review}

\subsection{Market Orientation}

Market orientation helps firms adopt the most effective and efficient activities for the creation of superior value for buyers and thus continuous superior performance for the business [8]. The concept of market orientation has been approached from two perspectives: behavioral market orientation [9] and cultural market orientation [8]. Kohli \& Jaworski [9] defined market orientation as consisting of three behavioral activities: market intelligence generation, the dissemination of this intelligence across departments in the organization and responsiveness to intelligence. This paper adopts the behavioral concept of market orientation proposed by Kohli \& Jaworski [9], and follows the general trend in the literature from the perspective of the organization itself because this concept has been previously employed in small business studies [10]. The dimensions of the concept are described as follows.

Intelligence generation refers to the collection and assessment of both customers' current and future needs, together with the impact of government regulation, competitors, technology and other environmental forces. Intelligence dissemination must be communicated and disseminated throughout an organization in both a formal and informal way. The firm must have an effective way to disseminate the intelligence generated and thus it is vital that different departments collaborate in such intelligence dissemination efforts. Responsiveness involves the responsiveness of the firm to the market intelligence generated, and disseminated. Responsiveness should involve the 
selection of target markets, designing and providing products and services to meet customers' current and expected needs, and the distribution and promotion of the products or services.

\subsection{Business Performance}

Business Performance is a multidimensional construct, comprising two broad measures: judgmental performance (for example, customer service loyalty) and objective performance (for example, ROA)[11]. A substantial volume of literature reveals that market orientation is associated with judgmental performance, and more specifically, with both long-run and short-term profitability, expressed as return on assets [8] market growth rate, and sales growth. However, objective measures of performance, such as gross operating profit, market share and capacity utilization have been also found to be related to market orientation. Scholars have noted that while judgmental measures of performance are important to profitability, objective measures of performance provide the link to profitability in service organizations [12]. By being market oriented, a firm can keep existing customers satisfied and loyal, attract new customers, accomplish the desired level of growth and market share and, consequently, achieve desirable levels of business performance.

\subsection{Innovation}

Innovation refers to the process of generating, developing, and adopting a new item, idea, or behavior [13,14]. Innovation also plays an important role in a company's success. Deshpandé [15] suggested that innovation is related to better objective performance in market-oriented firms, while later research noted that market orientation creates a solid foundation for innovation in a company.

Innovation in service firms has received widespread attention in the literature [16] because service firms are likely to encounter difficulties in protecting their offers through patents and copyrights. Therefore, service firms need to continually innovate in order to enjoy a solid competitive advantage.

Meeus and Oerlemans [17] found that in a competitive market, a focus on continuous innovation is a better innovation policy than inactivity and gradual innovation. The relevance of innovation orientation to smaller businesses is a reflection of the transformation of modern market environments in which new product development and differentiation have become important aspects of the business development of many firms [18]. Smaller firms which adopt a low cost strategy are characterized by an internal orientation that focuses on cost effectiveness and production efficiency. On the other hand, smaller businesses which pursue a differentiation strategy introduce new products to better serve customers.

Research on the relationship between market orientation and performance outcomes has been largely based on work conducted in the early 1990s. Dawes [19] noted that a number of studies focused on market orientation and performance relationships, and that for several years, these studies have presumed that market orientation is linked to better firm performance. Wang, Chen \& Chen [20] investigated the relationship between total quality management, market orientation, and business performance by conducting a survey of 588 hotels in Taiwan. From the results of their work, a positive main effect relationship between market orientation and hotels performance were confirmed. Köseoglu, Parnell, \& Doyle [21] examined market orientation, strategy, and revenue growth in with data from 214 Turkish hotels and proposed that hotels were likely to increase their sales (performance outcomes) by engaging market orientation as strategy to build a differentiation position in a hotel industry. Pelham \& Wilson [22] found that small firms cannot compete successfully by duplicating the strategies and practices of large firms, but small firms could achieve sustainable competitive advantage by installing market-oriented behavior in employees.

\section{Research Methodology}

To achieve the objectives, a mixed-method was employed and the study began with quantitative followed by qualitative approaches. The small hotel segment was chosen for this study. First, the Thai government has strengthened SMEs in the tourism industry, in which the hotel segment is a key player, to become a mechanism for the sustainable development of economy, society, culture and environment. Second, in SME industries, the majority are small hotels at 65 percent, as reported by the Office of SMEs Promotion [2]. A small hotel is defined as a hotel operating for profit with less than 80 rooms.
Data were gathered from small hotels located in the Bangkok metropolitan region and provinces in the east of Thailand. We chose these areas owing to their potential growth in revenue structure and quantity. Thailand's Office of Small and Medium Enterprise Promotion provided a database containing a list of emails, websites, and contact persons. The target respondents were owners or managers in charge of marketing functions as these individuals make decisions based on their perceptions of market conditions.

A total of 400 self-administered questionnaires were mailed to either the owners or managers of hotels. A postage-paid return envelope was enclosed in order to improve the response rate. Of the 400 questionnaires, 212 completed questionnaires were returned, yielding a response rate of $53 \%$.

The sample size has to be large enough to provide statistical testing on the theoretical model. Sample size, as in any other statistical method, provides a basis for estimation of sampling error. The statistical method employed in this research was maximum likelihood (ML) estimation as contained in the AMOS computer software.

A review of the literature indicated that there are no generally accepted criteria for determining a specific sample size using maximum likelihood estimation or similar structural modelling techniques. It is generally regarded, however, that 100 is a practical minimum for ensuring the appropriateness of maximum likelihood estimation. Moreover, a rule of thumb is that the ratio of the sample size to the number of model parameters should be at least 5:1 [23]. Sample sizes should exceed 100 to 150 to ensure accurate parameter estimates [24] .The achieved sample sizes of 212 were thus considered sufficient for the analysis of the proposed model in this study.

\subsection{Measurements}

The survey was made up of multi-item measurements that were developed from the extant literature, and informal discussion with practitioners in the hotel industry. This study adopted the scale used by Kara, Spillan, and DeShields [10] and Kohli and Jaworski [9] for the measure of market orientation. Market orientation was measured using a second-order scale, including intelligence generation (five items), intelligence dissemination (five items), and responsiveness (five items). The scale measuring innovation (five items) was derived from AppiahAdu and Singh [25] and Verhees and Meulenberg [26]. This measurement scale considered the perceptions of managerial practitioners in the small hotel industry rather than those of their customers.

Respondents were asked to rate five items on a five-point Likert scale (" 1 = strongly disagree to 5 = strongly agree") for Intelligence generation (MG), Intelligence dissemination (MD), Responsiveness (MR), and Innovation (IV). The Cronbach's alpha ratings for the scale reliability of each construct were $0.905,0.905,0.896,0.932$ respectively (Table 1 ), indicating that the internal consistency among each of the constructs was acceptable, and above the lower limit of 0.7 recommended by Hair et al. [23] and Nunnally [27]. The third item (MG3) regarding intelligence generation was reverse coded in order to minimize the response set bias. A three-item scale of business performance, in which respondents were asked to rate three items on a five-point Likert scale $(1=$ "decreased more than $10 \%$ " to $5=$ "increased more than $10 \%$ "), was adapted from the research of Kumar, Subramanian, and Yauger [28] and Moorman and Rust [29]. In addition, before estimating a reliability test with the Cronbach's alpha, the first item was reverse coded in order to minimize response set bias.

To confirm content validity, the questionnaire items were reviewed by five academics who are knowledgeable in the marketing field and service industry. A pilot study was then conducted with 30 owners/managers of small hotels. An English version was translated into Thai and then translated back to ensure semantic conformity. The managers were asked to read and answer each question, then offer comments as to whether the questions could be improved. Adjustments were made based on their recommendations.

Table 1 Construct Reliability and Average Variance Extracted (AVE)

\begin{tabular}{|l|l|l|l|l|}
\hline Measure & \multicolumn{1}{|c|}{ Item } & $\begin{array}{l}\text { Std. } \\
\text { Loading }\end{array}$ & $\begin{array}{l}\text { Construct } \\
\text { Reliability }\end{array}$ & AVE \\
& & & \\
\hline
\end{tabular}




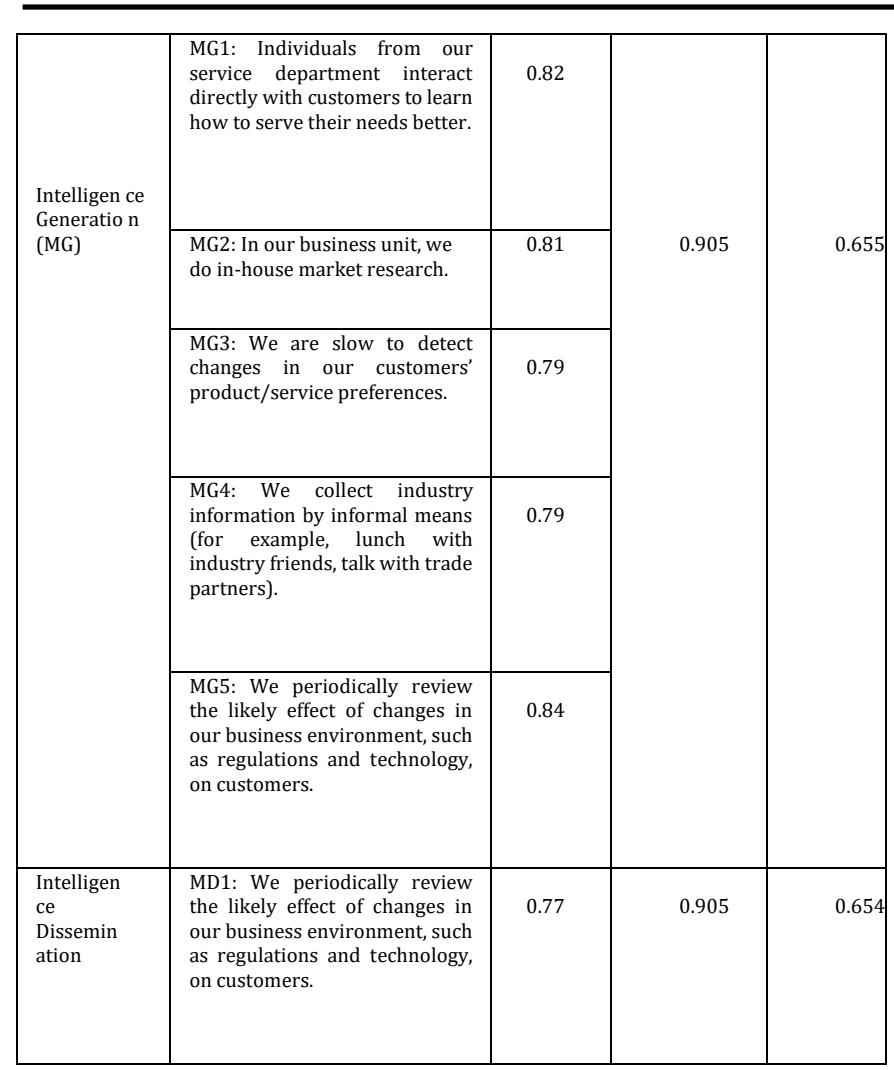

\begin{tabular}{|c|c|c|c|c|}
\hline \multirow[t]{4}{*}{ (MD) } & $\begin{array}{l}\text { Table 1.con } \\
\text { MD2: Marketing personnel in our } \\
\text { business unit spend time discussing } \\
\text { customers' future needs with other } \\
\text { functional departments. }\end{array}$ & 0.81 & & \\
\hline & $\begin{array}{l}\text { MD3: Our business unit periodically } \\
\text { circulates documents (for example, } \\
\text { reports and newsletters) that provide } \\
\text { information on our customers. }\end{array}$ & 0.80 & & \\
\hline & $\begin{array}{l}\text { MD4: When something important } \\
\text { happens to our major customer } \\
\text { market, the whole business unit } \\
\text { knows about it within a short period. }\end{array}$ & 0.82 & & \\
\hline & $\begin{array}{l}\text { MD5: Data on customer satisfaction } \\
\text { are disseminated at all levels in this } \\
\text { business unit on a regular basis. }\end{array}$ & 0.84 & & \\
\hline \multirow{4}{*}{$\begin{array}{l}\text { Responsi ve } \\
\text { ness } \\
\text { (MR) }\end{array}$} & $\begin{array}{l}\text { MR1: We periodically review our } \\
\text { product development efforts to } \\
\text { ensure that they are in line with what } \\
\text { customers want. }\end{array}$ & 0.80 & \multirow{4}{*}{0.896} & \multirow{4}{*}{0.632} \\
\hline & $\begin{array}{l}\text { MR2: If a major competitor was to } \\
\text { lunch an intensive campaign targeted } \\
\text { at our customers, we would } \\
\text { implement a response immediately. }\end{array}$ & 0.80 & & \\
\hline & $\begin{array}{l}\text { MR3: We are quick to respond to } \\
\text { significant changes in our } \\
\text { competitors' pricing structures. }\end{array}$ & 0.77 & & \\
\hline & $\begin{array}{l}\text { MR4: When we find out that } \\
\text { customers are unhappy with quality } \\
\text { of our service, we take corrective } \\
\text { action immediately. }\end{array}$ & 0.82 & & \\
\hline
\end{tabular}

\begin{tabular}{|c|c|c|c|c|}
\hline & $\begin{array}{l}\text { MR5: When we find that customers } \\
\text { would like us to modify a product or } \\
\text { service, the departments involved } \\
\text { make concerted efforts to do so. }\end{array}$ & 0.78 & & \\
\hline \multirow{5}{*}{$\begin{array}{l}\text { Innovatio n } \\
\text { (IV) }\end{array}$} & $\begin{array}{lll}\text { IV1: } & \text { We } & \text { place } \\
\text { mphasis } & \text { on } & \text { new business } \\
\text { development. } & \end{array}$ & 0.84 & \multirow{5}{*}{0.932} & \multirow{5}{*}{0.696} \\
\hline & $\begin{array}{l}\text { IV2: We constantly develop and } \\
\text { refine existing offers. }\end{array}$ & 0.85 & & \\
\hline & $\begin{array}{l}\text { IV3: We are innovative in our service } \\
\text { process. }\end{array}$ & 0.87 & & \\
\hline & $\begin{array}{l}\text { IV4: We like to experience with new } \\
\text { ways of doing things. }\end{array}$ & 0.82 & & \\
\hline & $\begin{array}{l}\text { IV5: We accept a challenge more } \\
\text { often than other hotels and } \\
\text { accommodation. }\end{array}$ & 0.80 & & \\
\hline \multirow{3}{*}{$\begin{array}{l}\text { Business } \\
\text { Performa nce } \\
\text { (BP) }\end{array}$} & $\begin{array}{l}\text { BP1: The cost of our business over } \\
\text { last year }\end{array}$ & 0.77 & \multirow{3}{*}{0.886} & \multirow{3}{*}{0.728} \\
\hline & $\begin{array}{l}\text { BP2: The revenue of our business } \\
\text { over last year }\end{array}$ & 0.89 & & \\
\hline & $\begin{array}{l}\text { BP3: The profit of our business over } \\
\text { last year }\end{array}$ & 0.89 & & \\
\hline
\end{tabular}

\section{Results}

\subsection{Measurement model}

Structural equation modeling (SEM) was employed to analyze the results. Confirmatory factor analysis (CFA) was used to assess the fit of the singlefactor congeneric models to the observed data. Byrne (2010) suggested that CFA is most appropriately applied to measures that have been fully developed and their factor structures validated. The measurement model in this study used AMOS

22.0 with Maximum Likelihood (ML) estimation. In addition, squared multiple correlation (R2) was used to evaluate the model and the suggested value exceeded 0.5 , which means the observed variable was reliable [30]. Construct reliability was estimated by calculating internal consistency among individual items of the measurement scales for the same construct. The reliability of the tested constructs ranged from 0.886 to 0.905 (Table 1), exceeding 0.7 , which is the lower limit generally agreed upon for construct reliability [23,29].

The following approaches were employed to test content and convergent validity. To achieve content validity, we chose established measurement scales that have been used in literature, then consulted with experts in the marketing field by administering a pre-test of the questionnaire. Convergent validity was assessed through factor loading estimations and the means of the average variance extracted (AVE). Bagozzi and Yi [31] recommended that all measured factor loadings must exceed

0.7 to ensure convergent validity. The factor loadings varied from 0.76 to 0.90 (see Table 1), all of them exceeding the suggested value of 0.7 . An AVE estimate of 0.5 or higher indicates acceptable validity for a construct's measure [32]. As illustrated in Table 1, all AVE values were higher than the necessary threshold; hence, convergent validity of all constructs was achieved.

\subsection{Structural model and hypotheses testing}

A structural model defines relationships among the unobserved constructs. It specifies which latent constructs directly or indirectly influence changes in the values of other latent constructs in the model. The model provided a satisfactory fit to the data $(\mathrm{CMIN} / \mathrm{df}=2.483, \mathrm{GFI}=$ $0.865, \mathrm{AGFI}=0.836, \mathrm{NFI}$

$=0.903, \mathrm{TLI}=0.932, \mathrm{CFI}=0.939, \mathrm{RMSEA}=0.065)$. The SEM analysis results of the hypothesized model presented in Table 2 show that, although market orientation does not have a direct effect on business performance, it does have an indirect effect on business performance via innovation. Hence, the hypothesis is supported. 


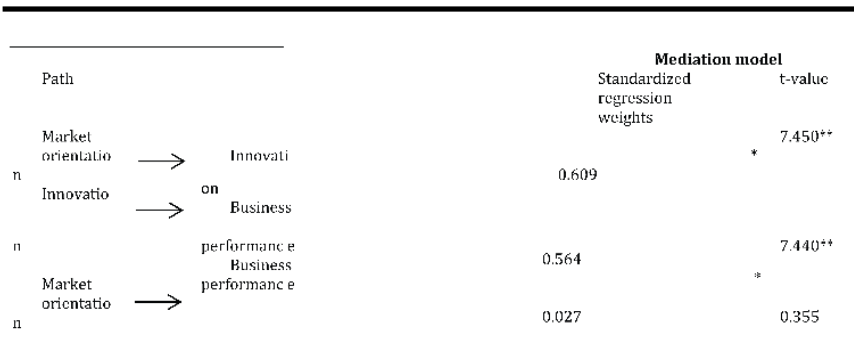

\section{Stage 2}

The aim of this stage is to confirm the effect of market orientation on small hotel business performance from the perspective of experts in the hotel industry. Therefore, a qualitative study was conducted. The sample of qualitative interviewees was hotel managers in charge of marketing functions. A snowball sampling technique was employed in the data collection phase because there was some resistance to participation due to the inconvenient timing of interviews and their tight schedules. Semistructured interviews with 22 small hotel managers were conducted. The semi-structured interview format can yield detailed and rich responses from respondents [33].

In the interviews, participants were invited to talk about how market orientation and innovation were undertaken in their hotels by asking questions. For example, "Does your hotel collect information about customer' needs from in-house market research or by having conversations with customers or trade partners?", "How does these activities benefit the hotel?", and "Has the management ever brought innovation into use in your hotel? Please give examples". All interviews were recorded on a digital recorder. The recordings were transcribed and the data were analyzed by employing content analysis following the procedures suggested by Busch et al. [34].

Nearly $60 \%$ of small hotels were situated in Bangkok, and the remaining $40 \%$ were in its metropolitan region; $82 \%$ of interviewees were male, and the average number of years of operation was 10 years. Content analysis began by identifying words, sets of words or phrases that were most used by interviewees. The collected data were then examined again in detail by reading through the text, writing down the concepts and classifying them into appropriate categories. Once the coding was finished, the data were examined. The results are described in the next section.

\section{Results from the Interview}

Table 3: In-depth Interview Findings

\begin{tabular}{|l|l|c|}
\hline \multicolumn{1}{|c|}{ Theme } & Participant ID & Frequency \\
\hline Market orientation & & \\
\hline - Intelligence Generation & $3,10,17,20,21,22$ & 6 \\
\hline - Intelligence Dissemination & $9,12,13,17,21,22$ & 6 \\
\hline - Responsiveness & $1,2,3,4,5,7,8,9,12,22$ & 5 \\
\hline $\begin{array}{l}\text {-Intelligence } \\
\text { semination } \\
\text { Responsiveness }\end{array}$ & $1,5,8,17,19$ & 11 \\
\hline Innovation & & $1,2,3,4,5,6,7,11,12,15,18,19,20,21,22$ \\
\hline Market orientation and innovation & $14,16,17,18,19,21$ & 6 \\
\hline
\end{tabular}

With regard to intelligence generation in small-sized hotels, there were 6 participants supporting this dimension. Some of the interviews are described below. Intelligence generation was also evident during the interview with participants 3 and 10: Usually, the marketing department conducts market research, about the new products/offerings of competitors. The marketing department provides feedback on the market information to other departments so that relevant department can create ideas about new and competing offerings and services. Participant 20 stated:

"When the sales department goes to the market to inspect and obtain some information about competitors and feel that our hotel offerings do not meet customer demands, or the pricing strategies, or the promotion programs are not performing well compared to the competitors, information from both formal and informal allows the departments in charge of these programs to think more about designing other relevant programs to respond to competitor attacks. Accordingly, we can defend our market and keep our customers."
Similar to intelligence generation, there were 6 participants supporting the notion that intelligence dissemination is a significant factor into the business performance of small hotels in Thailand. The interviewees made the following comments. Participant 9 stated that the information shared by the marketing department mostly includes market demands, market movements, consumer market insights, customer preferences and feedback, and product information. Participant 12 claimed:

"My marketing department, besides providing information to outsiders, supplies internal reports to other departments on a monthly basis. The purpose is to describe market demands, market trends, the size of the market as well as the purchasing power of customers, the partners we have contacted, and the potentiality of future partners. The other purpose of the shared information from the marketing department is to show the department's potential to other departments, to let them know what we have done, what we have achieved, and how we have succeeded."

Participant 13 gave an example: "For example, as a manager of a hotel, I talk about current competitor campaigns and I share my findings in meetings on a regular basis."

The responsiveness to customers' current and expected needs was highlighted via the qualitative analysis of the in-depth interviews. Nearly half of the participants agreed that responsiveness is an important dimension to be market-oriented for small hotels. However, of 11 participants who agreed with this concept, only 2 gave specific and clear examples. Participant 1 identified how responsiveness was conducted in his hotel as follows.

"For example, as marketing manager of the hotel, I suggested that, by improving our products or services, hotel management can deal with customer complaints to protect and maintain the hotel's reputation, have more updated market information to understand clients better, and know and understand customer demands to modify offerings."

Participant 22 discussed the importance of responsiveness to hotel performance:

"Take an example of one of our tour agent suppliers, who preferred to make reservations online. Their customer needs are sometimes changing and thus our tour agent has to change. Therefore, the responsibility of the marketing department is to understand the needs of our customer as well as our customers' customers. The purpose is to serve customers better to maintain a steady increase in sales."

Participants 4 and 8 opposed the idea that products or services adjusted according to individual preferences somehow were difficult to manage by hotel staff. However, once these jobs were achieved, it can help the hotel to serve customers in effective ways. In addition, qualitative analysis of the in-depth interviews found a relationship between intelligence dissemination and responsiveness. Five hotel managers pointed out the relationship between the two dimensions. For instance, Participants 17 , 1, 5, 8 talked about intelligence dissemination between the marketing department and other departments:

"Usually, the marketing department has to conduct market research about new the products or promotion campaigns of its competitors. They can provide feedback on the market information to relevant departments so that our hotel can create ideas about new and competing campaigns." Moreover, Participant 19 stated that:

"The marketing department usually contacts other departments to receive knowledge relevant to its work, such as developing their function rooms. The knowledge received from other departments such as facilities, list menus of food and beverages, the number of on-site mechanic staff, and internet or WIFI availability. Therefore, the marketing department can participate in some bidding programs. The purpose of sharing information is to improve the competitiveness of its pricing schemes in comparison to its competitors."

According to the views of most participants, there is a positive relationship between innovation and small hotel business performance. Among the major reasons why innovation enhanced organizational performance are cost reduction and market responsiveness. Fifteen participants insisted that innovation was important to their hotel's business performance. Some of views are presented below. Participant 1 , $2,3,7$ and 18 underlined the importance of innovation: One respondent said:

"Our industry is changing daily. If we do not innovate and do not invest in new products, we just have slow movement and cannot follow the market. 
If we innovate with a wide range of new products, we can boost our revenue and increase sales growth. In addition, innovation through diverse products or services allows us to satisfy various customer needs, and enhance customer choices".

Emphasizing the relevance of innovation to small hotel business performance, Participant 1, 5, 11 expressed similar views, and one stated that:

"The market is continuously changing. Everything is changing. Therefore, you cannot be successful if you are not moving. Thus, innovation surely drives better working outcomes and better performance in terms of the market, customers, as well as the business process, which is run smoothly and correctly".

In addition, Participants 6 and 22 stated that innovation can improve the image and reputation of our business in terms of serving customers and making them happy. Moreover, new, good ways of serving customers can impress the customers, and they will come back to stay at the hotel and

introduce us to their friends or other people. However, seven participants were relatively uncertain about implementing innovation which, in turn, affected business performance. These participants claimed that employees were somehow unsupportive and reluctant to change. In the participants' opinion, the responses of employees to innovation are summarized as follows.

"Implementing new ideas, the main problem is acceptance by staff. Employees don't want to change because it requires more work to do. In general, people are used to things being done a certain way so it is quite common that people are unwilling to change. Probably, the biggest challenge is getting staff to use new things."

One respondent further stated:

"When implementing new things or changes, our staff members don't like changes. At this point, staff training is possibly a right answer to loosen up their resistance. For example, I have a certain group of staff who is unfamiliar with technology. But I think they are quite good so I have to be very patient and diligent on my training."

Some participants insisted that innovation could be involved with market orientation to enhance small hotel business performance. The following are participants' opinion. Participants 14, 16, 17, and 19 indicated that: "Finally, if we innovate with new products, we can attract customers and boost our business performance. Another point is that innovation can help us to lower the cost of running our business. The reason is that innovation in the management process can help us to manage our business effectively as the process from the product-designing phase (Responsiveness) to the product implementation phase becomes smooth and efficient, of course, with knowledge sharing between different functions (Intelligence dissemination)."

Similarly, Participant 18 expressed the idea that the relationship between innovation and intelligence dissemination has a positive effect on cost reduction.

"Innovation can provide us with better outcomes such as a reduction in operating costs, and improved sales revenue. We will innovate. Otherwise, we will not innovate. If we choose an innovative solution, we should make sure the outcomes of the innovation are positive. Of course, innovation with strong connection and coordination between departments in terms of knowledge sharing (Intelligence dissemination) can make our business run effectively with more effective management systems and lower cost of operation."

Lastly, Participant 21 discussed the relationship between innovation and market responsiveness: "Many competitors and new entrants also stimulate many new market segments. Thus, the service market is very dynamic. Therefore, if our hotel does not have any innovation capability to adapt to the changes in the business environment or the industry movements, we will surely be behind the times, and then we will lose our market and then the consequences are bad."

\section{Discussion and Conclusion}

The results from quantitative and qualitative studies are consistent. The quantitative findings show that superior performance for small hotels depends on the fit between the market orientation deployed and the innovative culture present. A majority of interviewees agreed that innovation played a significant role in small hotel business performance.
The importance of the impact of innovation upon business performance among small hotels suggests the need for a better understanding of the organizational forces that determine the degree and shape the direction of innovative culture within small hotels. High emphasis on market orientation tends to be linked with a higher level of innovation because the commitment to market-oriented concept will force a firm to become more innovative. These results are of significance to hotel industry executives, who normally are able to employ innovation more easily and have a distinct possibility of adopting an innovative culture as a means to achieving a competitive edge.

Furthermore, it is also much easier for such managers to exploit the benefits of flexibility and simplicity. Business practitioners and executives of hotel industry should combine a sound market orientation, with an emphasis on innovation because such a combination is likely to result in higher

levels of business success rates. Small-sized hotels should adopt market orientation as a business strategy, even when the economy is flourishing. The more small hotels emphasize market-oriented offerings, the greater the likelihood that innovation will lead to higher business performance. This paper adds to the body of knowledge on the business performance of small hotels by exploring the effect of market orientation and innovation. Based on the empirical findings, small hotel businesses collected information by formal and informal means from existing customers, competitors and partners. Later, the information was shared by the marketing department with other departments in order to take action with regard to dealing with customer complaints or modifying offerings to meet customer preferences. As a consequence, small hotels are likely to defend their market and retain customer satisfaction so that their business performance could be maintained or even improved. Therefore, it is essential that small hotels should develop market orientation in terms of intelligence generation, dissemination, and responsiveness if they prefer superior business performance.

Small hotels reviewed changes in the business environment, particularly technology and learn from what competitors are doing, and then adjust their current products and services through incremental innovations. Owing to the importance of innovation and changes in today's business environment as stated in the result, it is strongly recommended that innovation should be implemented in small hotel properties to sustain their business performance. The examples of innovation are namely a digital booking platform and customer loyalty programs via social media (for example, Facebook, Twitter, mobile applications). Furthermore, considering the findings with respect to innovation suggested that small hotel employees were found to be a key to success in implementing innovation throughout the hotel, and later increase the hotel's business performance. Importantly, small hotel staff members are strongly recommended to be market-oriented by means of training. Also, small hotel managers could prepare staff for the innovation development process, helping them to realize that innovation is meant to make work more efficient rather than increasing their workload.

The results are useful for small hotels in terms of practical application. Small hotels can utilize the findings in order to develop offerings and services that are much more in line with Thai market needs. In addition, small hotel managers will be able to prepare short, medium, and longterm planning with regard to innovation for their properties.

The results of this study should be assessed while considering some limitations. Generalization of the findings should be conducted with caution as the sample size was relatively small. Nevertheless, this study presents a platform for future research on the effects of market orientation and innovation on the business performance of small hotels. Future research could consider conducting a quantitative study by using variables explored in this paper. Examining associations between market orientation, innovation and other important concepts such as entrepreneurial aspects could extend our understanding of business performance in the hotel sector.

\section{References}

[1] R. Turner: Travel \& Tourism World Economic Impact 2015. (Oxford Economics, London, United Kingdom 2016).

[2] Information on https://thai.tourismthailand.org/

[3] D. B. Audretsch: Small. Bus. Econ Vol.18 (2002), p. 13-40.

[4] A. Fiegenbaum and A. Karnani: Strateg. Manage. J Vol. 12 (1991), p. 101-114. 
[5] G. T. Hult, D. J. Ketchen and S. Slater: Strateg. Manage. J Vol. 26 (2005), p. 1173-1181. [6] Kasikorn Research Center: Econ. Analysis. Vol. 22 (2016), p. 1-6.

[7] Thai Hotels Association: Thailand Hotel Industry Survey 2015. (Thai Hotels Association Bangkok, Thailand 2017).

[8] J. C. Narver and S. F. Slater: J. Marketing Vol. 54 (1990), p. 20-35.

[9] A. K. Kohli and B. J. Jaworski: J. Marketing Vol 54 (1990), p. 1-18.

[10] A. Kara, J. E. Spillan and O. W. DeShields: J. Small. Bus. Manage Vol. 43 (2005), p. 105-118. [11] A. Sanjeev, E. M. Krishna and S. Chekitan: J. Serv. Mark Vol.17 (2003), p. 68-82.

[12] R. G Javalgi, T. W. Whipple, A. K. Ghosh and R. B. Young: J. Serv. Mark Vol. 19 (2005), p. 212-221.

[13] F. Damanpour: Acad. Manage. J Vol. 34 (1991), p. 555-590.

[14] G. Zaltman, R. Duncan and J. Holbeck: Innovation and Organization (John Wiley \& Sons, New York 1973).

[15] R. Deshpandé, J. U. Farley and F. E. Webster Jr.: J. Marketing. Vol. 57 (1993), p. 23-37. [16] M. I. Sanchez-Hernandez and F. J. Miranda: Eur. J. Manag. Vol. 14 (2011), p. 207-226. [17] M. T. H. Meeus and L. A. G. Oerlemans: Res. Policy Vol. 29 (2000), p. 41-58.

[18] N. Lado and A. Maydeu-Olivares: Int. Market. Rev Vol. 18 (2001), p. 130-145. [19] J. Dawes: Aust. J. Manage Vol. 25 (2000), p. 173-200.

[20] C. H. Wang, K.Y. Chen and S. C Chen: Int. J. Hosp. Manag Vol. 31 (2012), p. 119-129.
[21] M. A. Köseoglu, J. A. Parnell and J. D. Doyle: J. Travel. Tour. Mark Vol. 32 (2015), p. 1099-1116.

[22] A. M. Pelham and D. T. Wilson: Does Market Orientation Matter for Small Firms? (Marketing Science Institute, Massachusetts 1995).

[23] J. F. Hair, W. C. Black, B. J. Babin and R. E. Anderson: Multivariate data analysis: a global perspective 7th ed. (Pearson Prentice Hall, New Jersey 2010).

[24] M. Lei and R. G. Lomax: Struct. Equ. Modeling Vol. 12 (2005), p. 1-27.

[25] K. Appiah-Adu and S. Singh: (1998). Manage. Decis Vol. 36 (1998), p. 385-394.

[26] F. J. H. Verhees and M. T. G. Meulenberg: J. Small. Bus. Manage Vol. 42 (2004), p. 134-154. [27] J.C. Nunnally: Psychometirc Theory 2nd ed. (McGraw-Hill, New York 1978).

[28] K., Kumar, R. Subramanian and C. Yauger: J. Manage Vol. 24 (1998), p. 201-233. [29] C. Moorman and R. T. Rust: (1999). J. Marketing,Vol. 63 (1999), p. 180-197.

[30] B. M. Byrne: Structural equation modelling with AMOS: basic concepts, applications, and programming 2nd ed. (Routledge, New York 2010).

[31] R. P. Bagozzi and Y. Yi: J. Acad. Mark. Sci Vol. 16 (1988), p. 74-94. [32] C. Fornell and F. L. David: J. Marketing. Res Vol. 18 (1981), p. 39-50.

[33] M. B. Miles and A. M. Huberman: Qualitative Data Analysis: An Expanded Sourcebook (Sage Publications, Thousand Oaks, CA 1994).

[34] http://writing.colostate.edu/guides/research/content/ on 